\title{
MANUTENÇÃO DE BRINQUEDO EM PRAÇAS PÚBLICAS
}

\author{
MAINTENANCE OF PLAY EQUIPMENT IN A PUBLIC SQUARE
}

NAMIKI, Fabio

\section{RESUMO}

O artigo apresenta o jacaré, um dos brinquedos executados no âmbito do Programa Centros de Bairro, que foi responsável pela implantação de cerca de 50 praças na cidade de São Paulo entre 2002 e 2004. O conjunto dos brinquedos deste programa foi apresentado e analisado no mestrado "Manutenção de praças na cidade de São Paulo. Estudo de caso: brinquedos do programa Centros de Bairro", segundo metodologia que pode ser também aplicada para outros componentes de uma praça e mesmo para a praça em si. Espera-se que esta metodologia sirva como instrumento para o planejamento das ações de manutenção de praças e de mobiliários urbanos de modo geral.

Neste texto, são apresentadas informações (da mesma forma que seriam em um manual de uso, operação e manutenção) do projeto do brinquedo, obtidas junto aos responsáveis pelo programa, em entrevista com o executor dos brinquedos e através dos desenhos e documentos produzidos para a licitação e execução das peças. São também apresentadas as informações obtidas a partir das inspeções a campo e estimativas do custo de manutenção preventiva. Frente ao custo de reposição de um brinquedo novo, os valores da manutenção nos provam a importância econômica de tais ações.

Palavras-chave: Manutenção, brinquedos de playground, Programa Centros de Bairro.

\begin{abstract}
This article presents the jacaré (alligator) one piece of play equipments created by the Centros de Bairro Program, which was responsible for the construction of approximately 50 public squares in the city of Sao Paulo between the years of 2002 and 2004. The entire complex of play equipments was presented and analyzed in the Master's Degree Thesis, "Maintenance of Squares in the City of Sao Paulo. Case Study: Play Equipment of Centros de Bairro Program" according to methodology applied to other square components as well as to the square itself. This methodology is expected to be employed as an instrument for planning maintenance of squares and urban equipments in general.

The article presents information on the play equipment design (in the same fashion it would be on a use, operation, and maintenance reference manual). This information was gathered through the persons in charge of the program, interviews with the play equipment manufacturer, and drawings and documents produced for the purchase and production of the equipments. Also information that was collected through field inspections and estimated costs of preventive maintenance is presented in this article. In face of replacement costs of new play equipment, maintenance costs prove us the economic importance of such actions.
\end{abstract}

Key words: Maintenance, playground equipment, Centros de Bairro Program. 


\section{O brinquedo}

Os brinquedos do programa Centros de Bairro foram desenvolvidos exclusivamente para este programa pela equipe da Emurb - Empresa Municipal de Urbanização, coordenada pelo arquiteto Sérgio Marin, e contou com a consultoria do arquiteto Paulo Paiva. $O$ ponto de partida destes projetos foram os brinquedos feitos com sucata para o antigo parque Duque de Caxias (atual parque Celso Daniel) em Santo André.

São brinquedos para o uso simultâneo de várias crianças, com formas lúdicas, assemelhando-se a animais. Há escorregadores com formato de cobra e de dinossauro, gira-gira em forma de polvo, trepa-trepa em forma de elefante entre outros. No caso de São Paulo, os dois brinquedos mais estimulantes são os dois maiores - o jacaré e o sapo - que combinam diversas atrações como escorregador, trepa-trepa, ponte de madeira roliça presa por cabos de aço etc. A forma escultórica dos brinquedos não só desperta a curiosidade das crianças como também a dos adultos.

Apesar de exigirem mais manutenção que os brinquedos do programa Centro de Bairros (principalmente por utilizarem mais materiais consumíveis, como redes e cordas), em 2005, os brinquedos de Santo André recebem a devida manutenção e estão em pleno uso.

As qualidades de atratividade e de uso de um equipamento ou mobiliário urbano são difíceis de serem avaliadas e só podem ser julgadas, de fato, pela resposta dada pelo público. As visitas de campo feitas na época da execução das praças apontavam para um grande sucesso de apropriação dos brinquedos que se confirmou nas últimas inspeções. As praças do programa Centros de Bairro ainda estavam em obras e os brinquedos recém instalados já tinham fila para sua utilização. Depois de dois anos de uso e nenhum de manutenção, as crianças brincavam mesmo em equipamentos com a estrutura comprometida, com pontes caídas, com tubos corroídos.

Os brinquedos foram projetados e desenhados para execução pela equipe da Emurb. $\bigcirc$ cronograma apertado fez com que etapas desse processo fossem suprimidas: não foram feitos cálculos estruturais dos brinquedos; não foram realizados protótipos para verificação de possíveis falhas. Não havia também o conhecimento da existência de normas técnicas vigentes de segurança para brinquedos de playground.

A partir dos desenhos produzidos as construtoras realizaram os orçamentos para execução dos brinquedos nas empresas indicadas pela Emurb. Uma delas foi contratada pelas construtoras, uma empresa especializada na construção de cenários e acostumada a trabalhar com produtos diferenciados, únicos. Ajustes ao projeto foram realizados conforme a sua produção. Esse tipo de execução é mais informal, pois as decisões sobre detalhes podem ser tomadas durante a execução, diretamente com executor, sem compromisso com o processo e sem atribuições claras de responsabilidades. Não foram produzidos documentos nos quais a solução desses detalhes estejam registrados para averiguação posterior. A verificação só seria possível in loco. Essa é a forma como é realizada a maioria das obras no Brasil e que, claramente, merece revisão.

Foram produzidos brinquedos com estrutura de tubos metálicos e com estrutura de madeira roliça de eucalipto tratado, estes últimos em número bem menor. Apenas como dado, os brinquedos de madeira, dois anos após sua implantação e sem terem recebido qualquer manutenção, estavam em estado de conservação muito melhor que os de aço.

Os brinquedos foram adquiridos em 2002 pela prefeitura através das construtoras que executaram os projetos das praças que, por sua vez, compraram da empresa que fez os brinquedos. As atividades de manutenção que deveriam ser realizadas nos brinquedos não foram apresentadas em forma de documentos ou fornecidas de qualquer outra maneira aos órgãos que assumiriam essa função.

São apresentados a seguir o custo do brinquedo, que inclui a instalação nas praças. Os valores apresentados foram retirados dos relatórios de custos adicionais apresentados à prefeitura e correspondem aos valores finais aprovados. 
Tabela 1. Custo do brinquedo

\begin{tabular}{|l|l|}
\hline Brinquedo & Custo final com BDI \\
\hline Jacaré & R\$ 18.324,96 \\
\hline
\end{tabular}

Informações retiradas dos relatórios de preço adicional aprovados pela Emurb em 2002.

Será apresentado aqui o brinquedo multifuncional jacaré através de memorial descritivo, desenhos do projeto e fotos e descrita a manutenção recomendada. Após as inspeções realizadas constatou-se que os brinquedos do programa nunca receberam manutenção de espécie alguma e encontravam-se bem degradados.

\section{Características}

Uma condição assumida deste o projeto destes brinquedos foi a de que deveriam ser transparentes, telados ou abertos, nunca fechados. É uma forma de favorecer a segurança e, muito provavelmente, de manter mais limpos os brinquedos uma vez que, em áreas públicas, é comum encontrar dejetos em brinquedos fechados, como aqueles feitos de tubos de concreto.

O brinquedo jacaré possui estrutura de tubos de aço que formam arcos, circunferências e ondas. A estrutura principal em forma de arcos é disposta de forma não paralela o que faz o brinquedo serpentear. Sua estrutura é pintada de vermelho, amarelo e roxo.

○ jacaré possibilita várias formas de brincar. As brincadeiras desenvolvem equilíbrio e força através de atividades motoras como escalar, subir escadas marinheiro, se pendurar, atravessar pontes que balançam, escorregar, balançar e correr.

Este brinquedo desenvolve também a sociabilidade através do contato com outras crianças na mesma 'brincadeira'. Em conjunto, as crianças inventam novos jogos. Elas utilizam o brinquedo como casinha ou nave. São formas não sugeridas pelo brinquedo, mas que, graças à criatividade das crianças, são possíveis.

\section{O Projeto do Jacaré}

O jacaré é composto por seis módulos que sustentam 3 plataformas (1,40m, 1,83m e 2,23m), uma passagem tubular (túnel) e 2 pontes de madeira com alturas que variam de $0,90 \mathrm{~m}$ a $2,23 \mathrm{~m}$. Estes módulos estão interligados formando um longo corredor através do qual a criança passa por todas as atrações. O início deste percurso é feito por uma escada de roletes de madeira de um lado e o final é um largo escorregador na extremidade oposta. Trata-se do corpo do jacaré.
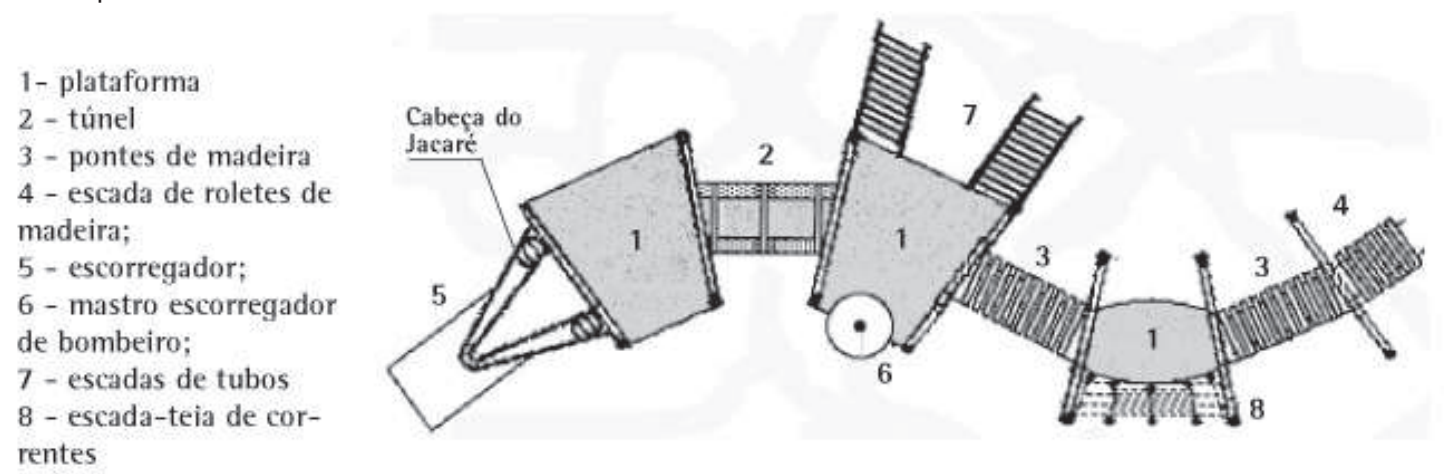

Figura 1: Desenho em planta do brinquedo jacaré.

Fonte: Emurb 


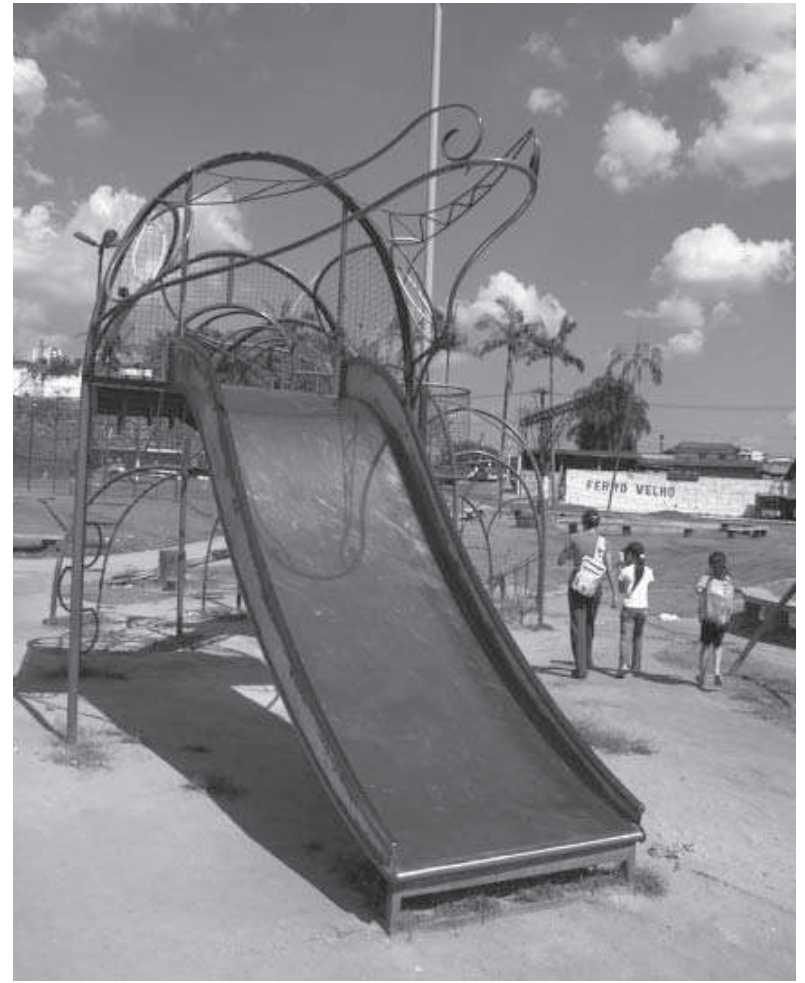

Figura 2: Brinquedo jacaré, escorregador. Dois tubos de aço de 2 1/2" curvos, ligados por tubos de aço quadrados, formam a estrutura de apoio da chapa de inox do escorregador que tem 1,20m de largura e comporta mais de uma criança ao mesmo tempo. Foto: Fabio Namiki

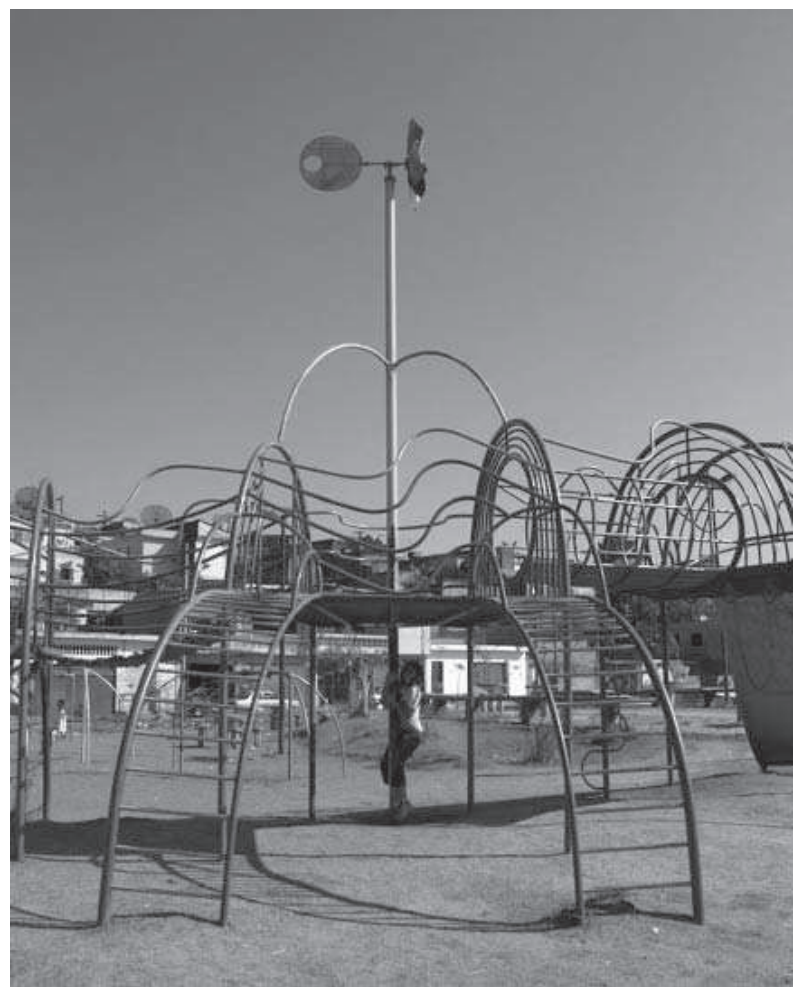

Figura 3: Brinquedo jacaré, mastro escorregador de bombeiro, feito com tubo de aço de 4" fixado à fundação através de solda em esperas chumbadas no concreto. Foto: Fabio Namiki
Uma escada-teia formada por correntes está ligada à lateral de uma das plataformas. Em uma outra plataforma tem-se, em uma das laterais, duas escadas marinheiro curvas, com degraus de tubos redondos, e, na outra lateral, um mastro que forma um escorregador tipo bombeiro. A plataforma na qual o escorregador está ligado possui 2,23 m de altura e, em sua parte inferior, alças soldadas para a criança se pendurar e, nos pilares, alças soldadas formando uma escada.

A estrutura principal do brinquedo foi executada em tubos industriais redondos de aço de 2 1/2" de diâmetro com espessura de parede de 2,65mm. É composta de 7 pórticos em forma de arcos de alturas variáveis. Os arcos são divididos internamente por tubos redondos de $11 / 2$ " de diâmetro onde serão conectadas plataformas, corrimãos, guarda-corpos e barreiras. Uma plataforma que não tem ponto de contato com a estrutura exterior é apoiada em arcos (tubo de $2 \mathrm{l} / 2^{\prime \prime}$ ) soldados internamente ao pórticos-arcos típicos da estrutura.

O brinquedo possui três plataformas que são formadas por quadros de tubos retangulares soldados aos pórticos onde são fixadas tábuas de madeira de eucalipto tratado $(30 \times 100 \mathrm{~mm}$ ou $30 \times 252 \mathrm{~mm}$ ).

A escada que está posicionada na parte de trás do brinquedo é formada por cabos de aço de $8 \mathrm{~mm}$ e degraus de roletes de madeira de eucalipto tratado. Dois cabos de aço estão esticados desde uma pequena plataforma até o chão e são presos (laçados) na parte superior por um tubo de aço. O tubo está soldado à estrutura da pequena plataforma na sua parte inferior. $\bigcirc$ cabo de aço está fixo na sua parte inferior a um vergalhão de $10 \mathrm{~mm}$. $O$ vergalhão está soldado nos pés da estrutura e fica semi-enterrado. Os roletes de madeira possuem dois furos por onde passam os cabos e o espaçamento é dado por pedaços de tubos de aço.

As pontes de madeira seguem o mesmo princípio construtivo da escada de roletes de madeira. É formada por quatro cabos de aço fixados nas suas extremidades às plataformas. A fixação é feita da mesma forma que a escada, através 

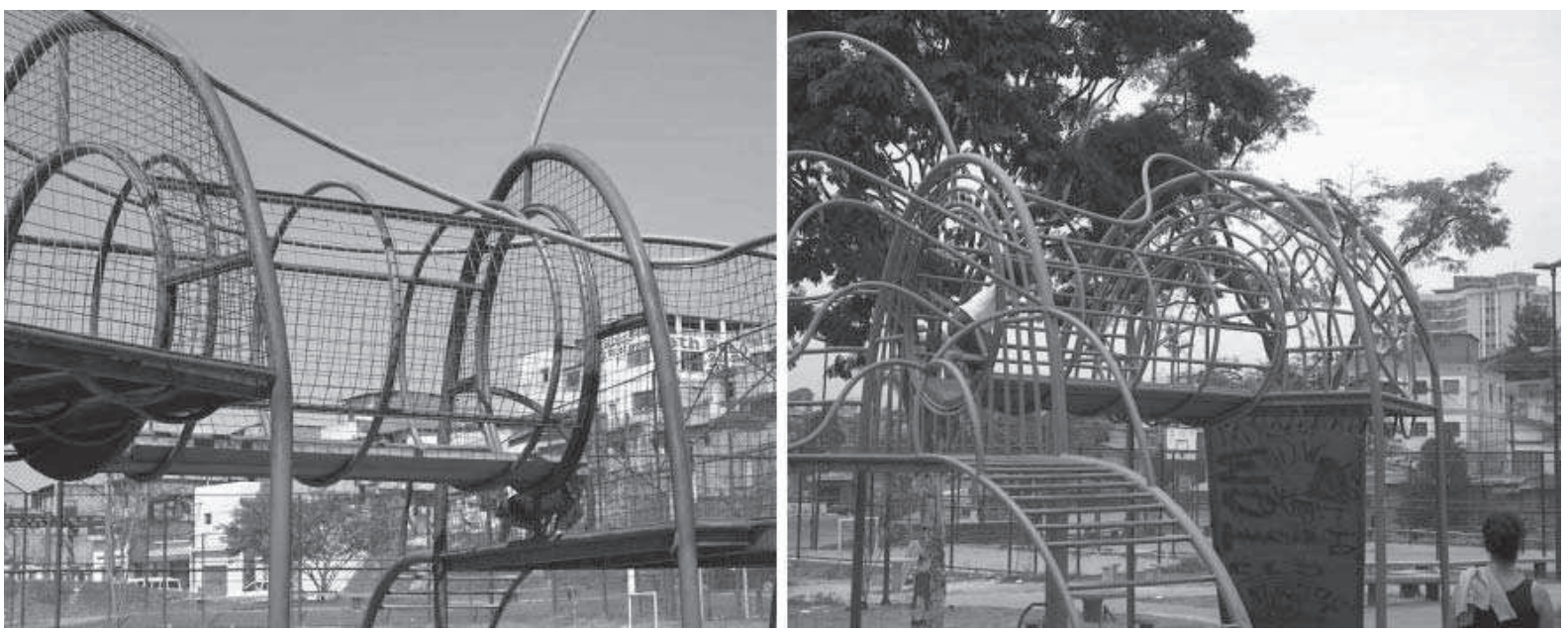

Figura 4: Corrimãos, guarda-corpos e barreiras. Os guarda-corpos e corrimãos são formados por tubos redondos de 1 " e 1 1/2" soldados aos pórticos e às divisões internas dos pórticos. As barreiras são formadas por telas de arame galvanizado $50 \times 50 \mathrm{~mm}$ soldados em uma barra de aço de diâmetro de 6,3mm e fixadas ao guarda-corpo e à estrutura. Foram colocadas barreiras na plataforma do escorregador, na do escorregador de bombeiro e no túnel que liga essas duas plataformas.

Foto: Fabio Namiki

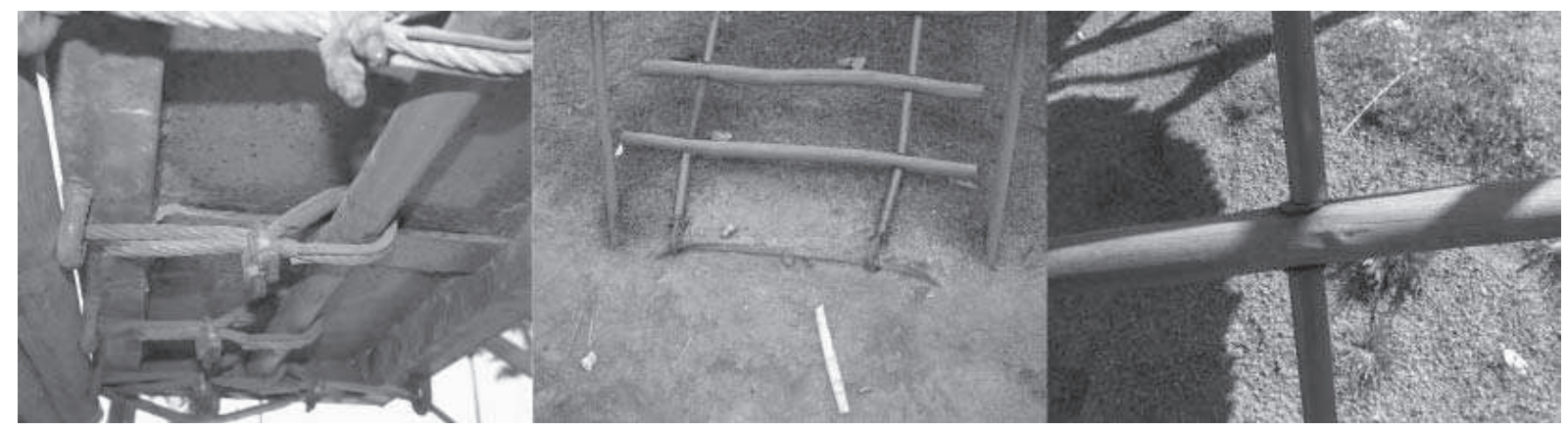

Figura 5: Detalhe da fixação dos cabos de aço da estrutura do brinquedo, da fixação dos cabos de aço na parte inferior da escada de madeira e do espaçador feito de tubo de aço para os degraus de madeira roliça.

Foto: Fabio Namiki

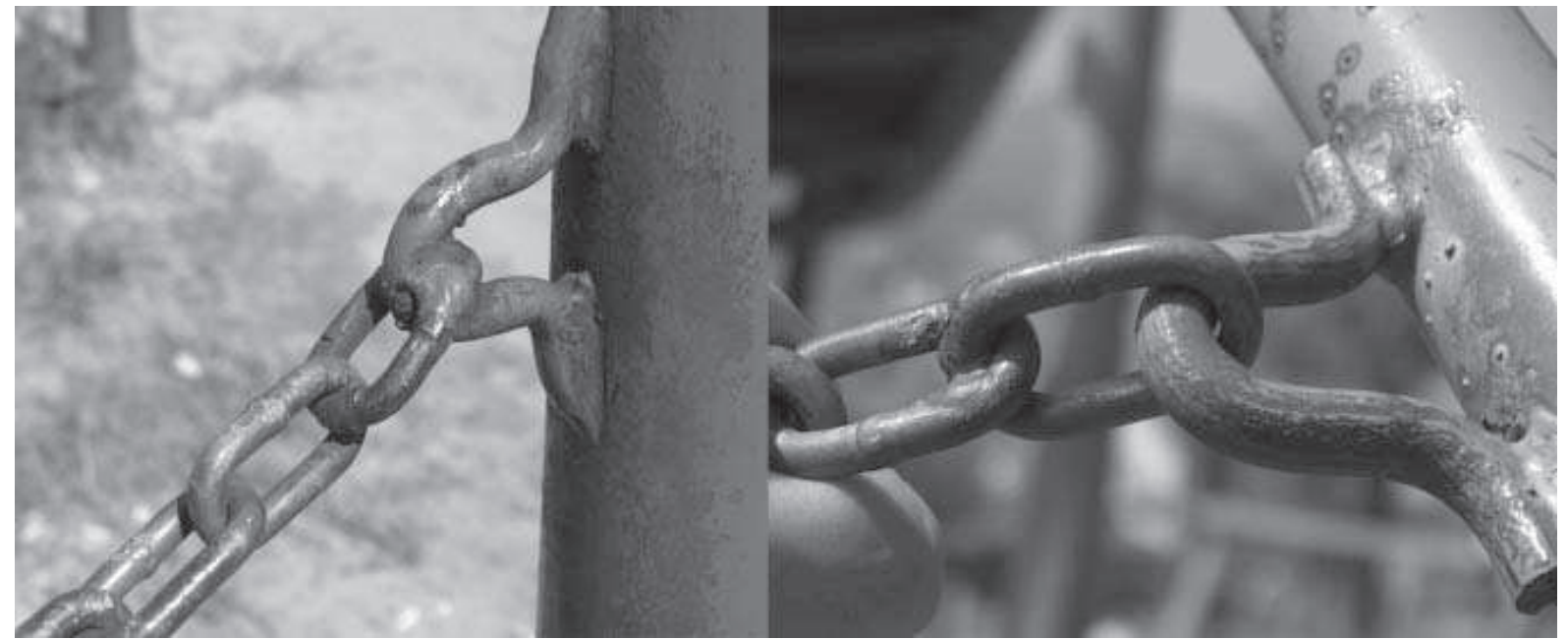

Figura 6: Detalhe de fixação das correntes Foto: Fabio Namiki 
de laços presos a tubos soldados na parte inferior das plataformas. Os roletes possuem quatro furos por onde passam os cabos de aço e não possuem espaço entre um e outro.

Chegando à plataforma que se localiza entre as pontes de madeira, correntes de aço galvanizado de $6 \mathrm{~mm}$ de espessura estão fixadas na estrutura, formando uma rede para escalar. As correntes são presas por pequenas alças soldadas à estrutura, feitas de vergalhão de aço liso de $10 \mathrm{~mm}$. Os elos das extremidades das correntes foram abertos e passados por dentro das alças e então soldados novamente. No chão, as correntes foram fixadas em alças chumbadas na fundação de concreto dessa mesma forma.

A fundação do brinquedo é composta por brocas manuais sob blocos de fundação de concreto armado. Foram chumbadas esperas metálicas nos blocos para a posterior fixação do brinquedo através de solda.

Os brinquedos metálicos foram pintados, segundo o fabricante, com tinta epóxi. Foi aplicada uma demão de fundo e uma demão de acabamento. A técnica de aplicação da tinta foi pistola (pulverização) na maior parte da estrutura e pincel em retoques realizados posteriormente. A maior parte da superfície foi preparada manualmente para pintura. Algumas soldas foram esmerilhadas para remoção de sobras e de pontas agudas, mas esse não foi um procedimento constante.

Foram utilizados quatro tipos de superfície de absorção de impacto: pedrisco misturado com serragem, pedrisco, areia ou grama, sendo utilizado predominantemente esta última. Entretanto, a grama não resistiu ao pisoteio intenso e morreu. Invariavelmente, em seu lugar, restou terra compactada.

\section{- Manutenção requerida}

A manutenção requerida pelos brinquedos da forma como foram construídos seria:

\section{- Manutenção rotineira}

Por se tratarem de estruturas de metal, atenção especial deve ser dada ao revestimento para evitar gastos maiores no futuro devido à corrosão.

São recomendados:

- Apertar os parafusos dos grampos de fixação dos cabos de aço. Como os outros parafusos e porcas do brinquedo foram soldados para evitar roubos, não é necessário seu ajuste.

- Repintar para corrigir pequenos defeitos de pintura sempre que forem percebidos danos. Deve-se agir o mais rápido possível. Para pintura, deve-se efetuar previamente limpeza da superfície a ser pintada (lavagem para remoção de gordura e pó, remoção de material de corrosão e tinta não aderida, etc) e então aplicar uma demão de fundo e, após o tempo de espera, aplicar a demão de acabamento.

- Lubrificar os pontos de contato dos metais tais como correntes e estrutura, cabo de aço e estrutura, ou dos eixos dos balanços e gangorra. A lubrificação forma uma camada contra corrosão, diminui o atrito e, por conseqüência, o desgaste nesses pontos.

- Limpar o brinquedo pelo menos duas vezes por ano. Em regiões mais agressivas deve-se aumentar a freqüência. A sujeira acumulada sobre a superfície, além de sujar os usuários, tem sais que são nocivos ao metal e segura a umidade na superfície aumentando as chances de corrosão. A limpeza deve ser efetuada com detergente e esponjas não muito abrasivas.

- Remover partes quebradas ou danificadas que possam por em risco o usuário. Por exemplo, se a corrente de um balanço corre o risco de se partir, deve-se trocá-la e, caso isto não possa ser feito imediatamente, deve-se tirar e remover o assento até que a troca seja realizada. 
- Manter a superfície de absorção de impacto:

- Restaurar o nível correto do material de amortecimento de quedas (areia, serragem etc) quando este apresentar buracos ou uma camada muito fina ou afofar a terra que estiver compactada;

- A limpeza da superfície deveria ser realizada diariamente. Deve-se observar se dejetos de animais não estão enterrados e efetuar sua remoção;

- Manter as áreas livres de obstáculos e outros produtos que possam ferir o usuário.

\section{- Manutenção periódica}

- Reposição do material consumível (cabos de aço, grampos, correntes etc), dependendo do seu estado de degradação ou do período de vida útil. A norma de cabos de aço recomenda a troca de todo o conjunto que exerça uma mesma função;

- Repintar para corrigir defeitos de pintura em áreas maiores ou repintura total, sempre que a proteção estiver desgastada. Deve-se efetuar previamente limpeza da superfície a ser pintada, aplicar de uma demão de fundo epóxi e, após o tempo de espera necessário, aplicar a demão de acabamento epóxi conforme a cor da peça. Deve-se levar em conta as condições climáticas para a execução desse serviço e o isolamento necessário para evitar o uso antes do tempo de cura da tinta.

- Reparos de soldas;

- Reposição de componentes estruturais defeituosos e de partes desgastadas ou com defeitos.

\section{Custos}

\section{Previsão de custos para a manutenção anual}

Os custos estimados para realização dos serviços descritos serão apresentados e transformados em uma fração do custo de reposição do brinquedo. Foram divididos em custos da manutenção rotineira e da manutenção periódica, a partir das seguintes suposições:

- os componentes consumíveis são trocados a cada dois anos com exceção do banco da gangorra. Para este item a troca é estimada para cada 4 anos;

- os serviços de pintura rotineira compreendem o rendimento de um galão de tinta epóxi, ou seja, $30 \mathrm{~m}^{2}$, para $150 \mathrm{~m}$ de tubo de 2 1/2" por demão, distribuídos entre os cinco brinquedos, proporcionalmente ao seu peso em aço;

- o serviço de limpeza das estruturas é realizado duas vezes ao ano e o tempo gasto é de uma hora e meia para o brinquedo jacaré;

- serviços de reposição e solda correspondem a 2,5\% do peso de aço utilizados no brinquedo jacaré.

\section{Tabela 2. Peso em aço do brinquedo}

Peso em aço dos brinquedos

\begin{tabular}{|l|l|}
\hline Tipo de brinquedo & Aço utilizado \\
\hline Jacaré & $1473,21 \mathrm{~kg}$ \\
\hline
\end{tabular}

Dados fornecidos pela empresa Cinestand, executora dos equipamentos.

Os valores dos gastos com manutenção anual dos equipamentos são: 
Jacaré

componentes consumíveis $=R \$ 281,70$

pintura - material $^{* * *}=\mathrm{R} \$ 54,62$ mão de obra**** $=\mathrm{R} \$ 163,87$

limpeza - mão de obra $=3 \mathrm{~h} \times 2,75^{* *}=\mathrm{R} \$ 8,25$

serralheria $-36,83 \mathrm{~kg} \times \mathrm{R} \$ 7,50^{*}=\mathrm{R} \$ 276,22$

total previsto anualmente $=\mathrm{R} \$ 784,66$

custo de reposição atualizado para o ano de $2005=R \$ 21825,32$

porcentagem do custo de reposição $=3,6 \%$

*custo da execução de estrutura metálica por kg de material para o mês de julho de 2005 segundo a revista

Construção e Mercado da revista PINI. O preço inclui material + mão de obra + equipamento.

** custo da hora da mão de obra de um ajudante de serviços gerais.

*** custo médio do galão de tinta epóxi para acabamento para o mês de julho de $2005=R \$ 125,00$.

***** custo de mão de obra de pintura $1 \mathrm{~m}^{2}$ de superfície de estrutura metálica tubular para o mês de julho de 2005

segundo a revista Construção e Mercado da revista PINI. $=R \$ 12,50$.

O custo de reposição foi atualizado por uma média de inflação de $6 \%$ ao ano.

\section{Comparação de custos de manutenção}

Foram realizadas inspeções utilizando-se a planilha proposta em dez praças, com intuito de verificar a situação atual dos brinquedos e a funcionalidade dos mesmos. Nas inspeções pôdese constatar que não foi realizada manutenção nos brinquedos nos dois anos e meio de uso. As intervenções que ocorreram foram ações comunitárias como a realizada na Praça do Encontro, na qual um morador comprou tintas e convenceu os skatistas a colaborarem na pintura dos brinquedos. $O$ estado de degradação encontrado é, em parte, resultado de detalhes de projeto e de execução mal resolvidos mas a manutenção periódica teria garantido menor degradação e melhores condições de uso.

Para uma comparação com os custos de uma manutenção preventiva, foram estimados os custos para a recuperação dos brinquedos no estado em que se encontravam por ocasião das inspeções. Nas fichas de inspeção, além da avaliação por nota, um espaço era destinado para a descrição dos trabalhos necessários na manutenção dos equipamentos.

Foi escolhida para realização das estimativas de custo a Praça do Trabalhador devido ao estado de degradação avançado que se encontrava. Para ela foram levantados os seguintes custos:

\section{Tabela 3. Resultado da inspeção realizada na Praça dos Trabalhadores.}

\section{Praça do Trabalhador}

\begin{tabular}{|c|c|c|}
\hline $\begin{array}{l}\text { Jacaré } \\
\text { Parte do equipamento }\end{array}$ & Índice de degradação & Urgência de intervenção \\
\hline Estrutura & 1 & A \\
\hline Revestimento & 1 & A \\
\hline Degraus e piso de madeira roliça de eucalipto tratado & 10 & C \\
\hline Tábuas de madeira de eucalipto tratado & 7 & A \\
\hline Cabos de aço & 1 & A \\
\hline Correntes & 1 & A \\
\hline Parafuso, porcas, etc. & 1 & A \\
\hline Catavento, gira-gira & 5 & B \\
\hline Superficie de absorção de impacto & 1 & A \\
\hline \multicolumn{3}{|c|}{ 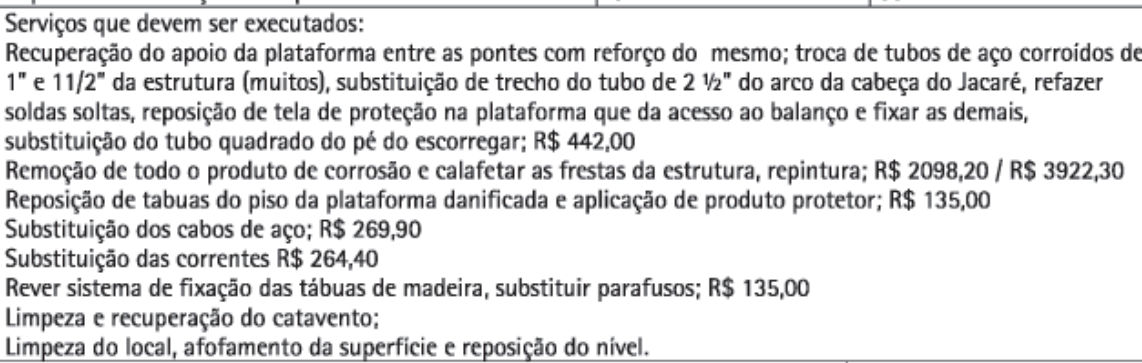 } \\
\hline Custo estimado: & & $2 \$ 3344,50 / R \$ 5168,60$ \\
\hline
\end{tabular}




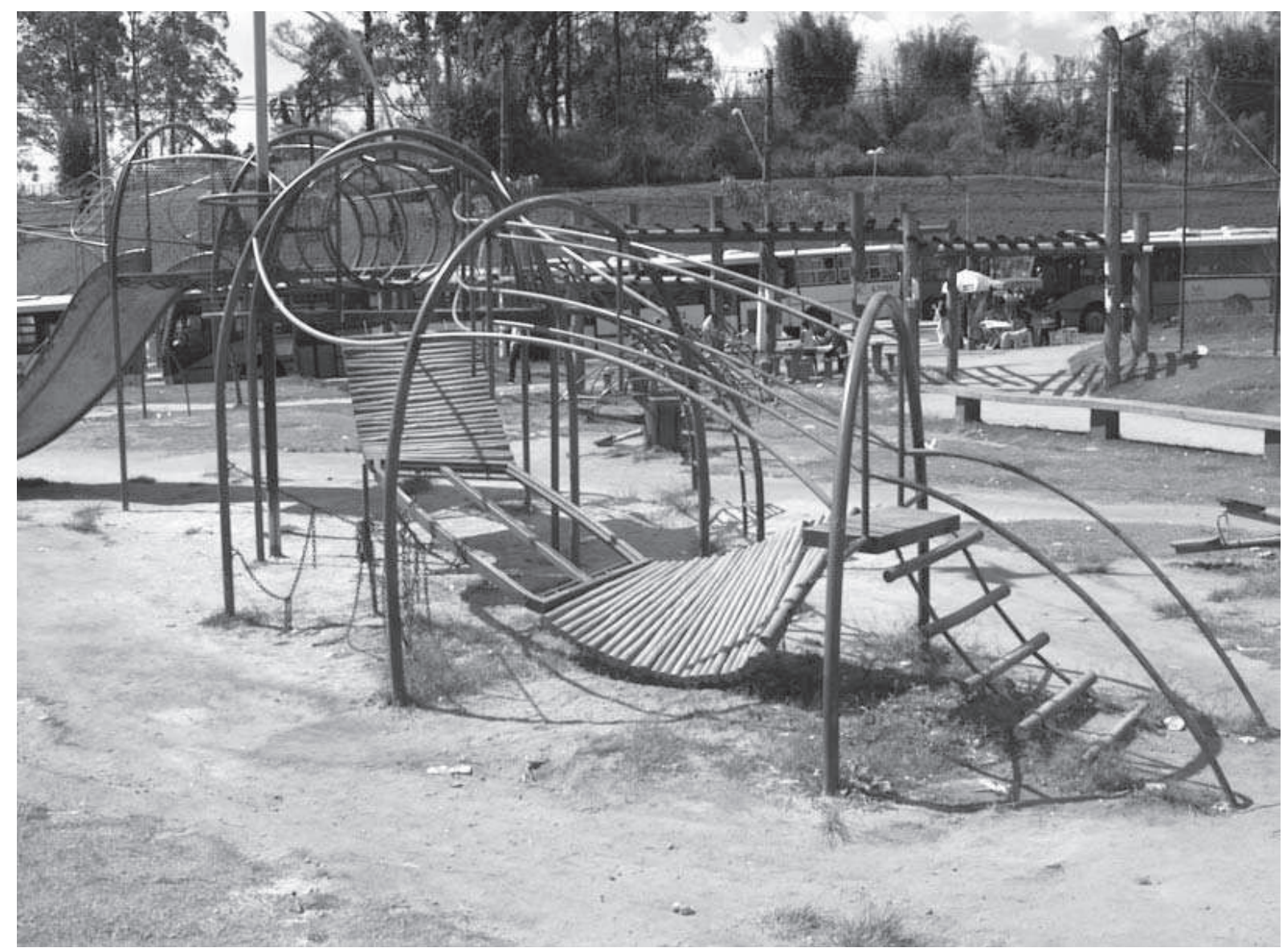

Figura 7: Brinquedo jacaré na Praça dos Trabalhadores. A plataforma não agüentou os esforços.

Foto: Fabio Namiki

O custo total estimado para fazer a manutenção dos brinquedos da Praça do Trabalhador no estado de degradação em que se encontrou foi de $R$ \$ 6.980,74. Os custos anuais estimados para a manutenção dos brinquedos dessa praça somam $\mathrm{R} \$ 1.690,85$ que, multiplicados pelo período de 2 anos e meio, resultam em $\mathrm{R} \$ 4.620,22$. A falta de manutenção ao longo deste período acarretou na elevação dos custos da manutenção a ser feita hoje em 51\%.

Se tivesse sido tomado maior cuidado na fase de produção, a degradação dos equipamentos teria sido menor, diminuindo os custos estimados. Se a durabilidade fosse aumentada, a estimativa dos custos anuais com a manutenção também seriam reduzidos, pois as substituições e consertos seriam menos freqüentes.

A execução de um sistema de pintura especial para as áreas de maior agressividade do meio é a única correção ao projeto que representaria um aumento significativo nos custos finais do brinquedo. Comparando-se o custo entre o sistema de pintura utilizado e o sistema de pintura proposto (para as áreas de maior agressividade do meio), o custo do segundo é em média $87,4 \%$ superior. Os brinquedos teriam um acréscimo de aproximadamente $11,5 \%$ no seu valor de reposição. Porém, é preciso avaliar o quanto a durabilidade do conjunto aumentaria e quanto tempo uma pintura daquele tipo resistiria sem reposição completa. A manutenção anual requerida pelo sistema proposto é a mesma do sistema epóxi de baixa espessura. Os custos anuais de manutenção dos dois sistemas de pintura seriam os mesmos.

Em relação ao custo de reposição das praças, a manutenção dos brinquedos representa muito pouco. Para a Praça Wilson Moreira da Costa, do mesmo programa, que teve seu custo de execução estimado em $R \$ 387.550,00$, o custo anual da manutenção dos brinquedos de estrutura metálica de $R \$ 1.397,79$, corresponde a $0,3 \%$ do custo da execução (ou de reposição). 
O domínio de informações na etapa de projeto que minimizem e facilitem as ações de manutenção pode prevenir o surgimento de falhas nos brinquedos que comprometem a vida útil dos equipamentos e colocam em risco a segurança dos usuários.

\section{Bibliografia}

ABNT - Associação Brasileira de Normas Técnicas. NBR 14350. Parte 1: Requisitos e métodos de ensaio. Segurança de brinquedos de playground. Rio de Janeiro: ABNT, 1999.

NBR 14350. Parte 2: Diretrizes para elaboração de contrato para aquisição/fornecimento de equipamento de playground. Segurança de brinquedos de playground. Rio de Janeiro: ABNT, 1999.

GNECCO, Celso. Manutenção da pintura em edifícios de aço. In: X SIMPÓSIO NACIONAL DE TECNOLOGIA DA CONSTRUÇÃO: A MANUTENÇÃO NA CONSTRUÇÃO CIVIL, 1995, São Paulo. Anais..., São Paulo: Edusp, 1989, p.115-128.

JONH, V. M. Comunicação Técnica 2349 - Uso, operação e manutenção da estrutura construída. In: 1 O ENCONTRO NACIONAL DA COMUNICAÇÃO TÉCNICA 1 DA ANTAC, 1990, Porto Alegre. Anais..., Porto Alegre, 1995, p. 4553.

; BONIN, L. C. Comunicação Técnica 2316 - Princípios de um sistema de manutenção. In: SEMINÁRIO SOBRE MANUTENÇÃO DE EDIFÍCIOS, 1988, Porto Alegre, 1988. Anais..., Porto Alegre: UFRGS, 1988, p. 126-38.)

; CREMONINI, R. A. Comunicação Técnica 2287 - Manutenção dos edifícios: Uma visão sistêmica. 10으 SIMPÓSIO NACIONAL DE TECNOLOGIA DA CONSTRUÇÃO: A MANUTENÇÃO DA CONSTRUÇÃO CIVIL, 1995, São Paulo. Anais..., São Paulo: Epusp, 1989, p. 115-128.

Comunicação Técnica 2315 - Custos de Manutenção. In: SEMINÁRIO SOBRE MANUTENÇÃO DE EDIFÍCIOS, 1998, Porto Alegre. Anais..., Porto Alegre: UFRGS, 1995, p. 32-51.

LEE, Reginald. Building maintenance management. Londres: Collins, 1987.

LIMA, Catharina P. C. S.; PELLEGRINO, Paulo R. M. Aplicação da APO no espaço livre urbano. In: ANTAC - Associação Nacional de Tecnologia do Ambiente Construído. Avaliação de Sistemas Construtivos e Pós-Ocupação. São Paulo: ANTAC, 1993.

ORNSTEIN, S. Walbe; BRUNA, Gilda Collet; LIMA, Catharina Pinheiro Cordeiro dos Santos. Uma experiência interdisciplinar - Avaliação Pós-Ocupação (APO) como metodologia de projeto dos espaços públicos e semipúblicos. São Paulo: FAUUSP, 1994.

ROSSO, Teodoro. Economia da construção. Racionalização da construção. São Paulo: FAUUSP, 1980.

SAKATA, Francine Gramacho. O projeto paisagístico como instrumento de requalificação urbana. 2004. Dissertação (Mestrado) - Faculdade de Arquitetura e Urbanismo, Universidade de São Paulo, São Paulo, 2004.

SEELEY, Ivor H. Building maintenance. Londres: MacMillan, 1982.

SILVA, Maria Angélica C. Avaliação de custo global em edificios. In: X SIMPÓSIO NACIONAL DE TECNOLOGIA DA CONSTRUÇÃO: A MANUTENÇÃO NA CONSTRUÇÃO CIVIL, 1989... São Paulo. Anais..., São Paulo: Epusp, 1989.

SILVA, Reinaldo Roesch da. Custos de manutenção: Reflexos das decisões nas diferentes fases do processo de construção. In: SIMPÓSIO SOBRE MANUTENÇÃO DE EDIFíCIOS, 1988... Porto Alegre. Anais..., Porto Alegre: UFRGS, v. 2, 1988, p. $131-141$.

\section{Contratos}

EMURB - Empresa Municipal de Urbanização. Processo n. 018110100 - Normas de participação. São Paulo: Emurb, 2001.

Relatório de análise de preço adicional n. 021/2002. São Paulo: EMURB, 2002.

Relatório de análise de preço adicional n. 051/2002. São Paulo: EMURB, 2002.

Relatório de análise de preço adicional n. 088/2002. São Paulo: EMURB, 2002.

Agradecimentos à Emurb por disponibilizar as informações que permitiram as avaliações feitas neste estudo. 


\title{
ESPAÇOS DE LAZER EM ÁREA NON AEDIFICANDI: UMA EXPERIÊNCIA DIDÁTICA EM PAISAGISMO
}

\author{
NOBRE, Paulo José Lisboa \\ Arquiteto, Professor de Paisagismo do Curso de Arquitetura e Urbanismo da Universidade Federal do Rio \\ Grande do Norte - UFRN, Mestre em Arquitetura e Urbanismo pelo PPGAU/ UFRN. \\ E-mail: paulonobre@ufrnet.br
}

\section{PESSOA, Maria Florésia}

Arquiteta, Professora de Planejamento Urbano do Curso de Arquitetura e Urbanismo da Universidade Potiguar - UNP, Mestre em Arquitetura e Urbanismo PPGAU/UFRN. E-mail: mariafloresia@aol.com

\section{RESUMO}

Natal é uma cidade com características ambientais marcantes. A legislação urbanística tem procurado preservar as características da paisagem local delimitando "Áreas de Controle de Gabarito", destinadas a proteger o valor cênico de algumas partes da cidade. Em 1979, foi9 criada uma área "Non AEdificandi" para proteger a paisagem da Praia de Ponta Negra, uma das mais famosas vistas da cidade. Desde então, o mercado imobiliário, os construtores e os proprietários da área em questão têm exercido constante pressão no sentido de abolir ou modificar este instrumento legal. Em contrapartida, a administração pública apresentou um novo projeto no qual tenta contemplar interesses públicos e privados. Este trabalho se constitui numa tentativa de inserir a Universidade nessa polêmica. Estudantes de Arquitetura,Planejamento Urbano e Estatística de duas Universidades de Natal (UFRN e UNP), contribuíram com o processo coletando dados e produzindo informações. Ao final os estudantes apresentaram sua solução particular para o problema, no âmbito das disciplinas de Paisagismo e Planejamento Urbano. incorporando-os num debate urbano pungente e atual, através de uma parceria com a Secretaria Municipal de Urbanismo, e apresentarem soluções no âmbito das disciplinas de Paisagismo e Planejamento Urbano.

Palavras-chave: Paisagem urbana, arquitetura paisagística, planejamento urbano.

\begin{abstract}
Natal is a city with environment singularities. The urban legislation tried to preserve the features of the local landscape delimiting "Areas for Controlling Building High", destined to protect the scenic value of some parts of the city. In 1979 was created a "NonAEdificandi" area to protect the scenery of Ponta Negra beach, one of the most famous view of the city. Since this time, the real state market, the building constructers and the land owners of this area have exerted constant pressure in sense to abolish or to modify this legal instrument. Nowadays, the public administration presented a new project which try to answer public and private interests. This paper is the result of an inclusion of the University in this polemic issue. Architecture and Urban Planning and Statistic students of two universities of the city (UFRN and UNP), helped the process collecting data and producing information. The proposed of the investigation was to know the users of this area and their opinion about the subject. It was done together with the Public agency, Secretaria Especial de Meio Ambiente e Urbanismo. At the end, the students presented their particular solutions for the problem, inside the disciplines of Landscaping and Urban Planning.
\end{abstract}

Key words: Urban scenery, landscaping, urban planning.

\section{A construção do debate urbanístico em Natal}

A Cidade de Natal foi fundada num ponto estratégico do litoral brasileiro, com a função de assegurar a defesa do território português. $\bigcirc$ assentamento urbano se desenvolveu tomando a forma determinada pela configuração do seu suporte físico. O Rio Potengi, o Oceano Atlântico 